\title{
SYNTHESIS OF NEW PYRROLINE NITROXIDES WITH ETHYNYL FUNCTIONAL GROUP
}

\author{
Györgyi Úr, Tamás Kálai, Mária Balog, Balázs Bognár,
}

Gergely Gulyás-Fekete, and Kálmán Hideg

\section{QUERY SHEET}

This page lists questions we have about your paper. The numbers displayed at left can be found in the text of the paper for reference. In addition, please review your paper as a whole for correctness.

Q1: Au: Please spell out EPR.

\section{TABLE OF CONTENTS LISTING}

The table of contents for the journal will list your paper exactly as it appears below:

Synthesis of New Pyrroline Nitroxides with Ethynyl Functional Group Györgyi Úr, Tamás Kálai, Mária Balog, Balázs Bognár, Gergely Gulyás-Fekete, and Kálmán Hideg 


\title{
SYNTHESIS OF NEW PYRROLINE NITROXIDES WITH ETHYNYL FUNCTIONAL GROUP
}

\author{
Györgyi Úr, ${ }^{1}$ Tamás Kálai, ${ }^{1,2}$ Mária Balog, ${ }^{1}$ Balázs Bognár, ${ }^{1}$ \\ Gergely Gulyás-Fekete, ${ }^{3}$ and Kálmán Hideg ${ }^{1}$ \\ ${ }^{1}$ Institute of Organic and Medicinal Chemistry, University of Pécs, \\ Pécs, Hungary \\ ${ }^{2}$ Szentágothai Research Centre, Pécs, Hungary \\ ${ }^{3}$ Department of Pharmacognosy, University of Pécs, Pécs, Hungary
}

GRAPHICAL ABSTRACT

$\mathrm{R}$ :
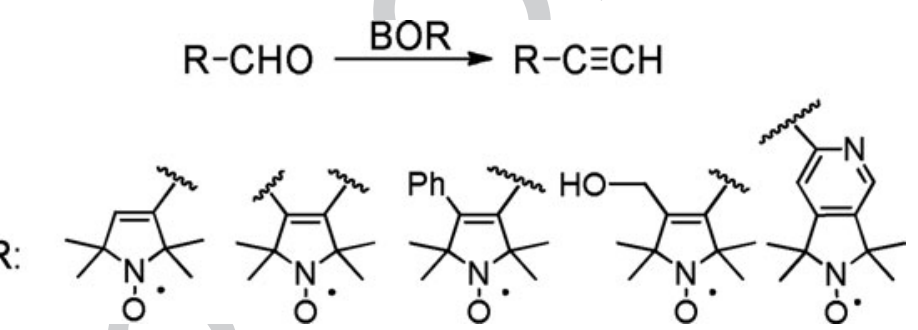

Abstract 3-Substituted and 3,4-disubstituted pyrroline nitroxides containing an ethynyl group or two ethynyl groups were achieved by the reaction of a paramagnetic aldehydes with dimethyl (1-diazo-2-oxopropyl)phosphonate (Bestmann-Ohira reagent). The new compounds containing an ethynyl group were found to be useful building blocks in Sonogashira coupling, cyclization, and cycloaddition reactions producing potentially "azido-specific" cross-linking spin labels, paramagnetic ligands, and polyradical scaffolds.

Keywords Alkynes; cyclization; ligand; nitroxides; Sonogashira coupling

\section{INTRODUCTION}

Nitroxides are stable free radical species with wide applications across a range of scientific disciplines including material science, biophysics, molecular biology, and medicine. ${ }^{[1]}$ Nitroxides are often applied as initiators for the preparation of functional and complex polymers, ${ }^{[2 \mathrm{a}]}$ oxidants in organic chemistry in their oxoammonium form, ${ }^{[2 b]}$ spin labels in surveying structure of biomolecules, ${ }^{[3]}$ building blocks for organic magnets, ${ }^{[4]}$ and dynamic nuclear polarization agents in NMR spectroscopy, ${ }^{[5]}$ just to mention but a few. The alkyne and terminal alkyne are functionally widely used in

Received May 30, 2015.

Address correspondence to Kálmán Hideg, Institute of Organic and Medicinal Chemistry, University of Pécs, Szigeti st. 12, 7624 Pécs, Hungary. E-mail: kalman.hideg@aok.pte.hu 


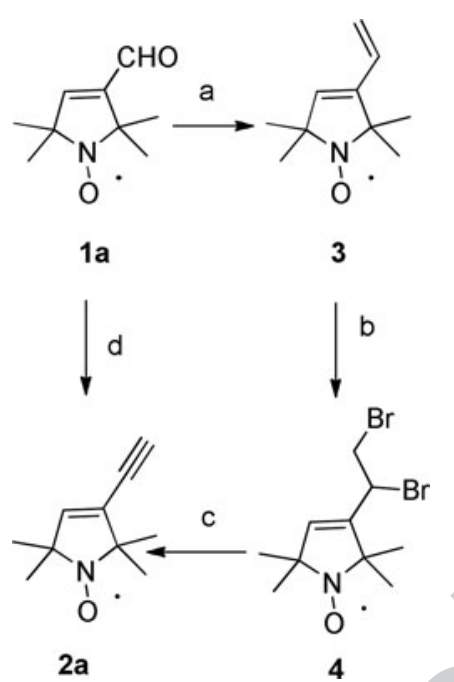

Scheme 1. Reagents and conditions: (a) see Ref. 24; (b) see Ref. 13; (c) see Ref. 13; (d) BOR (1.1 equiv.), $\mathrm{K}_{2} \mathrm{CO}_{3}$ (2.0 equiv.), $\mathrm{MeOH}, 3 \mathrm{~h}, 52 \%$, this paper.

organic synthesis, pharmaceutical science, material science, and bioorthogonal chemistry. ${ }^{[6 \mathrm{a}]}$ This functionality is also found in acetylenic natural products. ${ }^{[6 \mathrm{~b}]}$ The importance of ethynyl substituent containing nitroxides has also emerged in recent decades; they have been used for spin labeling of nucleic acids by Sonogashira coupling, ${ }^{[7]}$ synthesis of nanometer-sized paramagnetic oligomers, ${ }^{[8]}$ modification of biomolecules by azido-alkyne dipolar cycloaddition (click reaction), ${ }^{[9]}$ and construction of biradical species in Sonogashira and Glaser coupling reactions. ${ }^{[10]}$ In our laboratory we used Grignard reaction, ${ }^{[1]}$ Sonogashira cross coupling, ${ }^{[12]}$ and elimination of the corresponding 1,2-dibromoethanes ${ }^{[13]}$ to produce paramagnetic acetylenes. An ethynyl group formation by dimethyl (1-diazo-2-oxopropyl)phosphonate (Bestmann-Ohira reagent, abbreviated as BOR $)^{[14]}$ in the presence of the ambiphilic nitroxide moiety would be a useful, quick, and simple procedure, as it requires ambient temperature, $\mathrm{K}_{2} \mathrm{CO}_{3}$ base, dry methanol, and $1-2 \mathrm{~h}$ reaction time. To achieve ethynyl substituted pyrroline nitroxide 2a from aldehyde 1a with BOR can be considered more advantageous compared to our earlier, time- and reagent-consuming procedure via paramagnetic diene $3^{[24]}$ and dibromide $4^{[13]}$ (Scheme 1). We hypothesized that this reagent would be the only solution for synthesis of certain paramagnetic compounds, such as 3,4-diethynyl pyrroline nitroxide and 3-hydroxymethyl-4-ethynyl pyrroline nitroxide. Our aim was to increase the repertoire of accessible paramagnetic acetylenes capable for paramagnetic modification of biomolecules with Sonogashira cross-coupling or azido-alkyne click reaction.

\section{RESULTS AND DISCUSSION}

To introduce the ethynyl group into pyrroline nitroxides, we tested the reaction of dimethyl (1-diazo-2-oxopropyl)phosphonate ${ }^{[14]}$ with various paramagnetic aldehydes 1a-e e $^{[13,15-17]}$ to furnish the corresponding acetylenes $\mathbf{2 a - e}$ under mild conditions, for example, stirring the 1.1 equiv. BOR and the paramagnetic aldehydes 
in the presence of 2 equiv. $\mathrm{K}_{2} \mathrm{CO}_{3}$ in anhydrous methanol at room temperature. Fortunately, during the carbon-carbon formation reaction the nitroxide function remained intact. The yield changed from good to moderate, and from $\mathbf{1 a}^{[15]}$ aldehyde we got 2a 3-ethynylsubstituted pyrroline nitroxide, ${ }^{[13]}$ from aldehyde $\mathbf{1 b}^{[13]}$ we could synthesize the 3,4-diethynyl-pyrroline nitroxide $\mathbf{2 b}$, a bis-azidospecific cross-linking nitroxide, and from 4-phenyl-3-formyl-pyrroline nitroxide $1 \mathbf{c}^{[12]}$ we got the 3-ethynyl-4-phenyl-pyrroline nitroxide 2c. The 3-hydroxymethyl-4-formyl-pyrroline nitroxide $\mathbf{1 d}^{[16]}$ furnished the 4-ethynyl-3-hydroxymethyl-pyrroline nitroxide $\mathbf{2 d}$ and from paramagnetic picolyl aldehyde $1 \mathrm{e}^{[17]}$ we got the paramagnetic 2-ethynylpyridine 2e (Table 1). We tested the new acetylene compounds with 1,3-dipolar cycloaddition

Table 1. Synthesis of paramagnetic ethynyl compounds from paramagnetic aldehydes

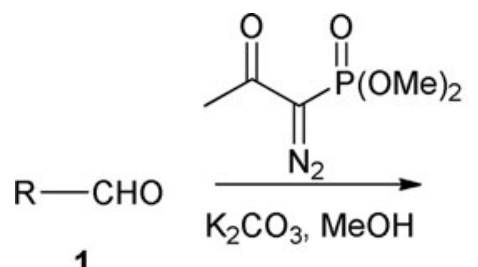

$$
\mathrm{R}-\mathrm{C} \equiv \mathrm{CH}
$$

1

2

Entry


reactions, ${ }^{[18]}$ Sonogashira coupling reaction, and functional group transforming reactions. The reaction of 3,4-diethynyl pyrroline nitroxide $\mathbf{2 b}$ with octylazide in the presence of $\mathrm{CuI}$ ( 0.6 equiv.) in dimethylsulfoxide (DMSO) yielded 3,4-bis (triazolyl)pyrroline nitroxide 5. Sonogashira coupling of compound $\mathbf{2 b}$ with paramagnetic vinyl iodide $\mathbf{6}$ in triethylamine-piperidine-dimethylformamide (DMF) mixture ${ }^{[8]}$ in the presence of $\mathrm{CuI}, \mathrm{PPh}_{3}$, and $\mathrm{Pd}(\mathrm{PhCN})_{2} \mathrm{Cl}_{2}$ furnished triradical 7, giving seven bands in EPR (see supplementary material) but with poor yield (9\%) (Scheme 2). This compound was prepared for further EPR studies, but its utilization as molecular magnet also can be considered.

The treatment of alcohol 2d under Appel reaction conditions ${ }^{[19]}$ with $\mathrm{PPh}_{3}$ and $\mathrm{CBr}_{4}$ in $\mathrm{CH}_{2} \mathrm{Cl}_{2}$ produced allylic bromide $\mathbf{8}$, which was converted to 3-acetylene-4azidomethyl-pyrroline nitroxide radical 9 in aqueous acetone with 2 equivalents $\mathrm{NaN}_{3}$. The ${ }^{1} \mathrm{H}$ NMR spectra data with four bands at 4.01, 3.31, 1.41, and $1.37 \mathrm{ppm}$; the 9 signals in ${ }^{13} \mathrm{C}$ NMR spectra; and the azido band $\left(2100 \mathrm{~cm}^{-1}\right)$ suggest that neither intramolecular nor intermolecular 1,3-dipolar cycloaddition reactions have occurred during the thermal conditions of nucleophilic substitution. As functional groups remained intact during synthesis, compound 9 can be regarded as a stable azide-acetylene cross-linking spin label reagent. Further nucleophilic substitution of compound $\mathbf{8}$ with excess $\mathrm{NaSSO}_{2} \mathrm{CH}_{3}$ in aqueous acetone gave compound $\mathbf{1 0}$ as a thiolspecific ${ }^{[20]}$ and azido-specific cross-linking spin label (Scheme 3). Compounds 9 and $\mathbf{1 0}$ contain nonactivated acetylenes, but water-soluble $\mathrm{Cu}(\mathrm{I})$ complexes $^{[21]}$ holding N-heterocyclic carbene might lead to a breakthrough in the bioconjugation of nonactivated acetylenes as well.
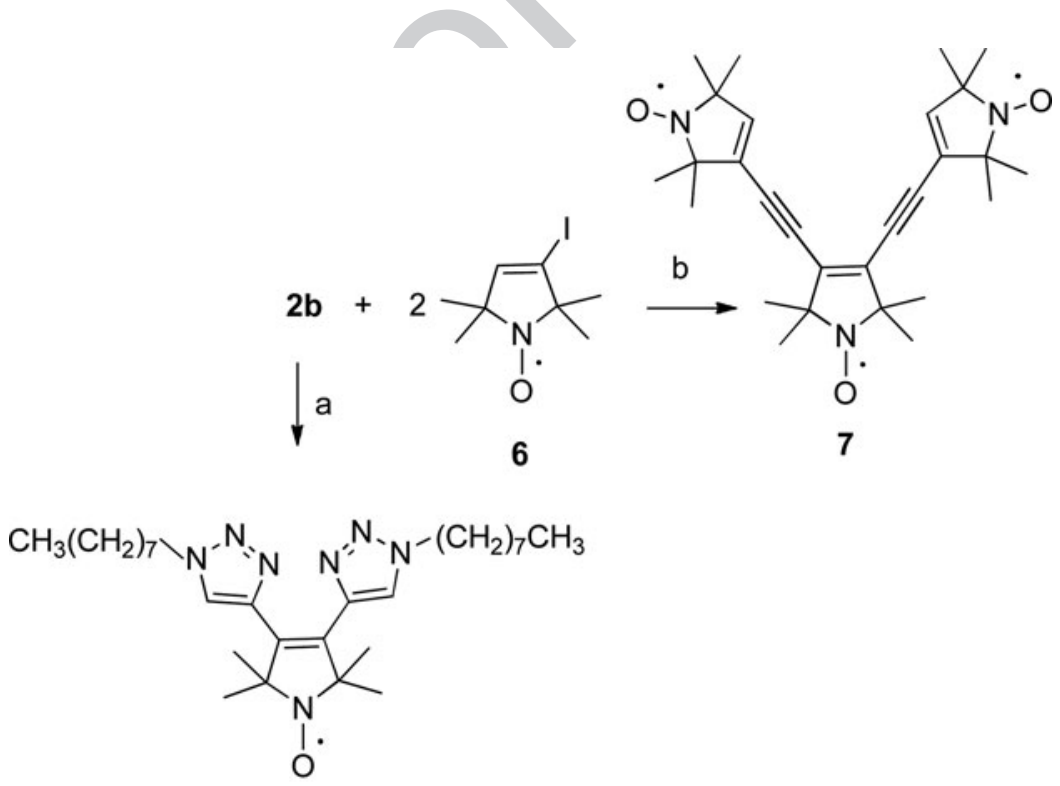

5

Scheme 2. Reagents and conditions: (a) octyl azide (2.5 equiv.), CuI ( 0.6 equiv.), DMSO, $40{ }^{\circ} \mathrm{C}, 1 \mathrm{~h}, 30 \%$; (b) 6 (2.0 equiv.), $\mathrm{Et}_{3} \mathrm{~N} /$ piperidine (5:1), DMF, $\mathrm{CuI}\left(0.05\right.$ equiv.), $\mathrm{PdCl}_{2}\left(\mathrm{PhCN}_{2}\left(0.1\right.\right.$ equiv.), $\mathrm{PPh}_{3}(0.05$ equiv.), $2 \mathbf{b}$ (1.0 equiv.), rt, $16 \mathrm{~h}, 9 \%$. 


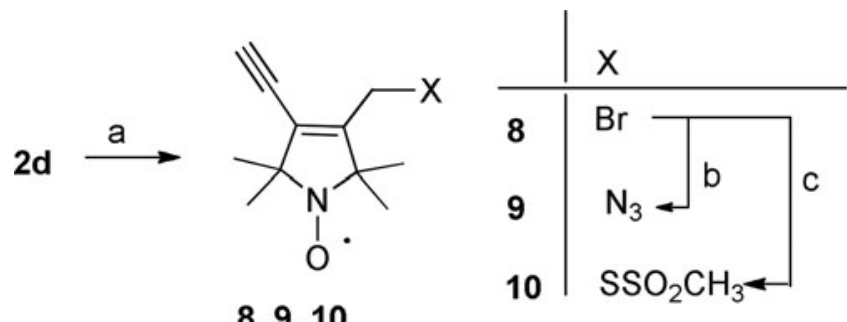

Scheme 3. Reagents and conditions: (a) 2d (1.0 equiv.), $\mathrm{CBr}_{4}$ (1.14 equiv.), $\mathrm{PPh}_{3}$ (1.42 equiv.), $\mathrm{DCM}, 0^{\circ} \mathrm{C}$ rt, $1 \mathrm{~h}, 45 \%$; (b) 8 (1.0 equiv), $\mathrm{NaN}_{3}$ (2.0 equiv.), water/acetone, $40^{\circ} \mathrm{C}, 3 \mathrm{~h}, 46 \%$; (c) 8 (1.0 equiv), $\mathrm{NaSSO}_{2} \mathrm{CH}_{3}$ (3.3 equiv), water/acetone, $40^{\circ} \mathrm{C}, 30 \mathrm{~min}, 32 \%$.

The Sonogashira reaction of paramagnetic 2-ethynyl pyridine $\mathbf{2 e}$ with 2-iodobenzaldehyde furnished compound 11, and cyclization in ammonia solution in $\mathrm{MeOH}$ in the presence of AgOTf catalyst ${ }^{[22]}$ with microwave heating gave the paramagnetic 2,2'-dipyridyl analog 12, as a paramagnetic ligand (Scheme 4). Although several paramagnetic ligands with phenanthroline and 2,2-dipyridyl moieties were published earlier, ${ }^{[23]}$ to the best of our knowledge it is unprecedented that the nitroxide moiety is annulated with one of the complex-forming rings, decreasing the mobility of the spin label unit. The complex formation of compound 12 with $\mathrm{Cu}^{2+}$ in acetonitrile was studied spectrophotometrically. Referring to the band at $351 \mathrm{~nm}$ (increasing with $\mathrm{Cu}^{2+}$ concentration) we have found $\mathrm{K}=13$ $\mathrm{dm}^{-3} / \mathrm{mol}$ association constant, and saturation occurred at 2:1 ligand/metal ratio (see the supplementary material).

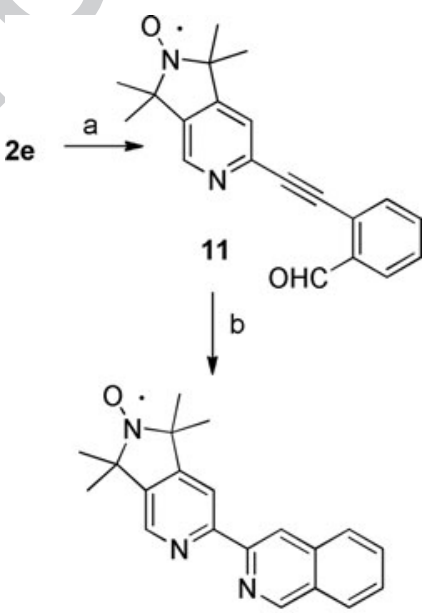

12

Scheme 4. Reagents and conditions: (a) 2-iodobenzaldehyde (0.9 equiv.), $\mathrm{CuI}$ (0.04 equiv.), $\mathrm{Pd}\left(\mathrm{PPh}_{3}\right)_{2} \mathrm{Cl}_{2}$ (0.016 equiv.), $\mathrm{Et}_{3} \mathrm{~N}, \mathrm{~N}_{2}$, rt, $15 \mathrm{~min}$, then $2 \mathrm{e}$ (1.0 equiv.), $50{ }^{\circ} \mathrm{C}, 20 \mathrm{~h}$, sealed tube, $36 \%$; (b) $\mathrm{AgOTf}(0.1$ equiv.), $\mathrm{NH}_{3} / \mathrm{MeOH}$ (excess), $\mu \mathrm{W}, 100^{\circ} \mathrm{C}, 10 \mathrm{~min}, 34 \%$. 
CONCLUSION

The application of Bestmann-Ohira reagent was extended to the synthesis of various acetylene-containing paramagnetic building blocks with new $\mathrm{C}$-C bond formation, but without alteration of the nitroxide moiety. The resulting new building blocks offered access to various scaffolds: cross-linking spin label reagents, a ligand, a triradical, and a bis(triazole) substituted nitroxide.

\section{EXPERIMENTAL}

Melting points were determined with a Boetius micro-melting-point apparatus and are uncorrected. Elemental analyses $(\mathrm{C}, \mathrm{H}, \mathrm{N}, \mathrm{S})$ were performed on Fisons EA 1110 CHNS elemental analyzer. Mass spectra were recorded on a Thermoquest Automass Multi. NMR spectra were recorded with Bruker Avance 3 Ascend 500 spectrometer. Chemical shifts are referenced to $\mathrm{Me}_{4} \mathrm{Si}$. Several representatives of paramagnetic compounds were reduced with 5 equivalents of hydrazobenzene/ radical, as NMR cannot be measured directly on paramagnetic compounds. Measurements were run at $298 \mathrm{~K}$ probe temperature in $\mathrm{CDCl}_{3}$ solution. ESR spectra were taken on Miniscope MS 200 in $10^{-4} \mathrm{M} \mathrm{CHCl}_{3}$ solution and all monoradicals gave triplet line $\mathrm{a}_{\mathrm{N}}=14.4 \mathrm{G} ; 7$ triradical gave 7 band-containing spectra with $\mathrm{a}_{\mathrm{N} 1}=14.5 \mathrm{G}$, $\mathrm{a}_{\mathrm{N} 2}=9.4 \mathrm{G}, \mathrm{a}_{\mathrm{N} 3}=5.4 \mathrm{G}$. The microwave-assisted reactions were carried out in Milestone MicroSYNTH labstation in a sealed tube ( 15 bar) with temperature control (fiber-optic probe). The total irradiation time is as indicated. The IR spectra were taken with Bruker Alpha FT-IR instrument with ATR support (ZnSe plate). The UV-vis spectra were taken with Specord 40 spectrophotometer with quartz cuvette. Flash column chromatography was performed on Merck Kieselgel 60 $(0.040-0.063 \mathrm{~mm})$. Qualitative thin-layer chromatography (TLC) was carried out on commercially available plates $(20 \times 20 \times 0.02 \mathrm{~cm})$ coated with Merck Kieselgel $\mathrm{GF}_{254}$. Compounds $\mathbf{1 a},{ }^{[15]} \mathbf{1 b},{ }^{[13]} \mathbf{1 c},{ }^{[13]} \mathbf{1 d},^{[13]} \mathbf{1 e},^{[16]} \mathbf{2 a},{ }^{[17]} \mathbf{3},{ }^{[24]} \mathbf{4},{ }^{[13]}$ and $\mathbf{6}^{[25]}$ were prepared according to published procedures; other reagents were purchased from Aldrich or Alfa Aesar. The BOR was purchased from Tokyo Chemical Industry or prepared according to Ref. $14 \mathrm{~b}$.

\section{General Procedure for Conversion of Aldehydes to Acetylenes (2a, 2b, 2c, 2d, and 2e)}

$\mathrm{K}_{2} \mathrm{CO}_{3}(552 \mathrm{mg}, 4.0 \mathrm{mmol}$ or $1.10 \mathrm{~g}, 8.0 \mathrm{mmol}$ for compound $\mathbf{2 b}$ ), dimethyl(1-diazo-2-oxopropyl)phosphonate $(422 \mathrm{mg}, 2.2 \mathrm{mmol}$ or $844 \mathrm{mg}, 4.4 \mathrm{mmol}$ for compound 2b) were added to a stirred solution of the aldehyde 1a (336 $\mathrm{mg}$, $2.0 \mathrm{mmol}$ ), 1b (392 mg, $2.0 \mathrm{mmol}), \mathbf{1 c}(488 \mathrm{mg}, 2.0 \mathrm{mmol}), \mathbf{1 d}(396 \mathrm{mg}, 2.0 \mathrm{mmol})$, or $1 \mathrm{e}(438 \mathrm{mg}, 2.0 \mathrm{mmol})$ in $15 \mathrm{~mL}$ of dry methanol. The reaction was stirred at room temperature until the consumption of aldehyde $(\sim 2 \mathrm{~h})$ at room temperature. The reaction mixture was diluted with $\mathrm{Et}_{2} \mathrm{O}(25 \mathrm{~mL})$, washed with an aqueous solution of $\mathrm{NaHCO}_{3}(5 \%)$, dried over $\mathrm{MgSO}_{4}$, filtered, and evaporated and the residue was purified by flash column chromatography (hexane/ $\mathrm{Et}_{2} \mathrm{O} 3: 1$ or hexane/EtOAc 2:1) to furnish compounds as yellow solids. 


\section{3-Ethynyl-2,2,5,5-tetramethyl-2,5-dihydro-1H-pyrrol-1-yloxyl Radical (2a)}

Yield: $170 \mathrm{mg},(52 \%), \mathrm{mp} 122-123^{\circ} \mathrm{C}\left(\mathrm{mp} 122-123^{\circ} \mathrm{C}^{[13]}\right), \mathrm{R}_{\mathrm{f}} 0.4$ (hexane/ $\left.\mathrm{Et}_{2} \mathrm{O}, 2: 1\right) ;{ }^{1} \mathrm{H}$ NMR $\left(500 \mathrm{MHz}, \mathrm{CDCl}_{3}+(\mathrm{PhNH})_{2}\right) \delta=1.42(\mathrm{~s}, 6 \mathrm{H}), 1.51(\mathrm{~s}, 6 \mathrm{H})$, $3.15(\mathrm{~s}, 1 \mathrm{H}), 6.06(\mathrm{~s}, 1 \mathrm{H}) .{ }^{13} \mathrm{C} \mathrm{NMR}\left(125 \mathrm{MHz}, \mathrm{CDCl}_{3}+(\mathrm{PhNH})_{2}\right) \delta=25.2(2$ $\left.\mathrm{CH}_{3}\right), 25.8\left(2 \mathrm{CH}_{3}\right), 69.1\left(2 \mathrm{C}_{\text {quat }}\right), 71.7\left(2 \mathrm{C}_{\text {quat }}\right) 78.4\left(\mathrm{C}_{\text {quat }}\right), 80.6(\mathrm{CH}), 127.2\left(\mathrm{C}_{\text {quat }}\right)$, $141.2(\mathrm{CH})$. IR (neat): $\bar{\nu}=3194,3049,2977,2092,1613 \mathrm{~cm}^{-1}$. MS $(70 \mathrm{eV}): \mathrm{m} / z=164$ $\left(\mathrm{M}^{+}, 28\right), 149$ (42), 134 (100), 119 (73). Anal. calcd. for $\mathrm{C}_{10} \mathrm{H}_{14} \mathrm{NO}$ : C, 73.14; H, 8.59, N 8.53. Found: C, 73.25; H, 8.60; N, 8.69.

\section{3,4-Diethynyl-2,2,5,5-tetramethyl-2,5-dihydro-1 $\mathrm{H}$-pyrrol-1-yloxyl Radical (2b)}

Yield: $180 \mathrm{mg}(42 \%) ; \mathrm{mp} 149-150{ }^{\circ} \mathrm{C} ; \mathrm{R}_{\mathrm{f}}=0.62$ (hexane $/ \mathrm{Et}_{2} \mathrm{O} 2: 1$ ); ${ }^{1} \mathrm{H}$ NMR $\left(500 \mathrm{MHz}, \mathrm{CDCl}_{3}+(\mathrm{PhNH})_{2}\right) \delta=1.50(\mathrm{~s}, 12 \mathrm{H}), 3.51(\mathrm{~s}, 2 \mathrm{H}) .{ }^{13} \mathrm{C} \mathrm{NMR}$ $\left(125 \mathrm{MHz}, \mathrm{CDCl}_{3}+(\mathrm{PhNH})_{2}\right) \delta=24.9\left(4 \mathrm{CH}_{3}\right), 70.9\left(2 \mathrm{C}_{\text {quat }}\right), 85.6\left(2 \mathrm{C}_{\text {quat }}\right)$ $100.0(2 \mathrm{CH}), 133.4\left(2 \mathrm{C}_{\text {quat }}\right)$. IR (neat): $\bar{\nu}=3213,2978,2089,1466,1435 \mathrm{~cm}^{-1}$; MS (70 eV) $m / z=188\left(\mathrm{M}^{+}, 43\right), 173$ (62), 138 (13), 128 (100), 51 (70). Anal. calcd. for $\mathrm{C}_{12} \mathrm{H}_{14} \mathrm{NO}$ : C, 59.01; H, 5.61; N, 9.18. Found: C, 59.10; H, 5.55; N, 9.25.

\section{FUNDING}

We are grateful to Hungarian National Research Fund (OTKA K81123, K104956) for financial support.

\section{SUPPLEMENTAL MATERIAL}

Full experimental details and ${ }^{1} \mathrm{H}$ NMR (of compounds 2c, 2d, 5, 9, 11), ${ }^{13} \mathrm{C}$ NMR (of compound 9), EPR (of compound 7), UV-vis (of compound 12), MS (of compounds 2c, 2d, 2e, 5, 7, 8, 9, 10, 11, 12), and IR (of compounds 2c, 2d, $2 \mathrm{e}, \mathbf{5}, \mathbf{7}, \mathbf{8}, \mathbf{9}, \mathbf{1 0}, \mathbf{1 1}, \mathbf{1 2})$ data can be accessed on the publisher's website.

\section{REFERENCES}

1. Likhtenstein, G.; Yamauchi, J.; Nakatsuji, S.; Smirnov, A. I.; Tamura, R. Nitroxides: Applications in Chemistry, Biomedicine, and Materials Science; Wiley-VCH: Weinheim, 2008

2. (a) Tebben, L.; Studer, A. Angew. Chem. Int. Ed. 2011, 50, 5034-5068; (b) Kelly, C. B.; Ovian, J. M.; Cywar, R. M.; Gosselin, T. R.; Wiles, R. J.; Leadbeater, N. E. Org. Biomol. Chem. 2015, 13, 4255-4259.

3. Shelke, S. A.; Sigurdsson, S. T. In Structural Information from Spin-Labels and Intrinsic Paramagnetic Centres in the Biosciences; C. Timmel and J. R. Harmer (Eds.); Springer: Berlin, 2013.

4. Ratera, I.; Veciana, J. Chem. Soc. Rev. 2012, 41, 303-349.

5. Fawzi, N. L.; Fleissner, M. R.; Anthis, N. J.; Kálai, T.; Hideg, K.; Hubbell, W. L.; Clore, G. M. J. Biomol. NMR 2011, 51, 105-114. 
6. (a) Gröst, C.; Berg, T. Org. Biomol. Chem. 2015, 13, 3866-3870; (b) Zhu, X.; Liu, J.; Zhang, W. Nat. Chem. Biol. 2015, 11, 115-120.

7. Frolow, O.; Endeward, B.; Schiemann, O.; Prisner, T. F.; Engels, J. W. Nucleic Acids Symp. Ser. 2008, 52, 153-154.

8. Böde, E. B.; Margraf, D.; Plackmeyer, J.; Dürner, G.; Prisner, T. F.; Schiemann, O. J. Am. Chem. Soc. 2007, 129, 6736-6745.

9. Kálai, T.; Hubbell, W. L.; Hideg, K. Synthesis 2009, 8, 1336-1341.

10. Kokorin, A. I.; Golubeva, E. N.; Mladenova, B. Y.; Tran, V. A.; Kálai, T.; Hideg, K.; Grammp, G. Appl. Magn. Reson. 2013, 44, 1041-1051.

11. Sár, P. C.; Jekő, J.; Fajer, P.; Hideg, K. Synthesis 1999, 6, 1039-1045.

12. Kálai, T.; Balog, M.; Jekő, J.; Hubbell, W. L.; Hideg, K. Synthesis 2002, 12, 2365-2372.

13. Kálai, T.; Balog, M.; Jekő, J.; Hideg, K. Synthesis 1999, 6, 973-980.

14. (a) Müller, S.; Liepold, B.; Roth, G. J.; Bestmann, H. J. Synlett 1996, 521-522; (b) Pietruszka, J.; Witt, A. Synthesis 2006, 24, 4266-4268.

15. Hideg, K.; Hankovszky, H. O.; Lex, L.; Kulcsár, G. Synthesis 1980, 12, 911-914.

16. Kálai, T.; Jekő, J.; Hideg, K. Synthesis 2000, 6, 831-837.

17. Kálai, T.; Balog, M.; Szabó, A.; Gulyás, G.; Jekő, J.; Sümegi, B.; Hideg, K. J. Med. Chem. 2009, 52, 1619-1629.

18. Rostovtsev, V. V.; Green, L. G.; Fokin, V. V.; Sharpless, K. B. Angew. Chem. Int. Ed. 2002, 41, 2596-2599.

19. Li, J. J.; Limberakis, C.; Pflum, D. A. Modern Organic Synthesis in the Laboratory; Oxford University Press: Oxford, 2007; p. 28.

20. Berliner, L. J.; Grünwald, J.; Hankovszky, H. O.; Hideg, K. Anal. Biochem. 1982, 119, 450-455.

21. Díaz Velázquez, H.; Ruiz Garcia, Y.; Vandichel, M.; Madder, A.; Verpoort, F. Org. Biomol. Chem. 2014, 12, 9350-9356.

22. Dell'Acqua, M.; Pirovano, V.; Confalonieri, G.; Arcadi, A.; Rossi, E.; Abbiati, G. Org. Biomol. Chem. 2014, 12, 8019-8030.

23. (a) Ulrich, G.; Ziessel, R. Tetrahedron Lett. 1994, 35, 1215-1218; (b) Bognár, B.; Jekő, J.; Kálai, T.; Hideg, K. Dyes Pigm. 2010, 87, 218-224.

24. Hideg, K.; Csekő, J.; Hankovszky, H. O.; Sohár, P. Can J. Chem. 1986, 64, 1482-1490.

25. Kálai, T.; Bognár, B.; Jekô, J.; Hideg, K. Synthesis 2006, 15, 2573-2579. 